\title{
INTERNATIONAL DISTRIBUTION OF EQUITY FUNDS AND MARKET EFFICIENCY
}

\author{
I. MAGAS
}

(Received:15 November 2000; revision received: 30 June 2001; accepted: 6 July 2001)

\begin{abstract}
The network of international capital markets is modeled as a global communications system, where information flows in one channel and funds flow in the other. Based on the fundamental logic of the measurement of information (Reza, 1992) and on the standard assumptions of the Capital Asset Pricing Model (CAPM) (Shapiro, 1999), we demonstrate that these markets operate at very large losses. Global markets are far less efficient than long-established domestic capital markets of developed countries, which do relatively well in transmitting information and funds. Along with the integration of national capital markets into a more tightly knit international network, however, major improvements in efficiency can be expected. Integration, though, implies a need for some kind of global regulations to help standardize the flow of information and the routines of pricing risk. Standardization in turn can be expected to decrease risks and increase the efficiency of distributing funds. From an information-theoretical perspective the introduction of mutually accepted regulations is desired, since it would boost the capacity utilization of the distribution system as such. A better-utilized communications system will bring faster clearing international markets and cheaper funds.
\end{abstract}

Keywords: global finance and regulation, international portfolio investment, information theory

JEL classification index: D4, E44, G14

\section{INTRODUCTION}

In the last two decades of the 20th century international capital markets have been characterized by dynamically increasing global distribution of funds. When combined with some unfortunate disturbances (often random events), however, the in-

1 An earlier version of this study has been submitted as an invited paper of the VIth Annual Conference of The European Association of Comparative Economics /EACES/, Barcelona, September 7-9, 2000.

Correspondence: I. Magas, International Business School, H-1021 Budapest, Tárogató u. 2-4. E-mail: imagas@tech.ibs-b.hu orimagas@ahol.com 
ternational capital markets generated not just local crises but intercontinental, financial "landslides" as well. The dampening of very risky local and international market disturbances is, in part, an information problem. In the light of recent developments in global finance (Eichengreen, 1999) and in information technology it comes as no surprise that in describing economic events, the demand for an information-theoretical approach is becoming increasingly pressing. This trend is strongly reflected in many seemingly different fields of the economics literature, Harsányi (1990), Khoury (1991), Lucas (1996), Bródy (1998), Gray (1999). We wish to present an information-theoretical approach for the modeling of global equity markets. One of our fundamental questions in the systems' perspective is whether upon examining the reorganization of international equity markets, what would an "external observer" see. It is our perception, that from this particular perspective, international equity markets do not appear to be efficient networks. They operate at low capacity and generate a lot of loss. It is our belief that on the way to better understand modern international capital markets, especially when it comes to handling its failures or crises, a communications approach can be of some help.

It is a matter of general knowledge that over the last two decades, the volume of capital flows related to international portfolio investments has dynamically increased. The demand to demolish the existing barriers to the international flow of capital is ever increasing, as is the need for some kind of harmonization of national regulation standards. Global financing is in need for some new rules of the game (Eichengreen, 1999). Equity markets are no exception. In the leading OECD countries, the benefits of efficient, domestic capital markets are beyond any doubt. However, with the creation of truly global equity markets, perhaps, these benefits can be further extended to other international seekers of funds, as well as to international savers in general. From a pure perspective of the system, it can be reasonably argued, that following a successful integration of major national capital markets into a much larger unit, a quasi-"global" network that features homogeneous rules of handling risk, substantial efficiency gains will be captured. Recent efforts of leading European stock exchanges, e.g. London LSE, Frankfurt's Deutsche Börse, to merge into an IX (International Exchange) with some of their European and transatlantic rivals (e.g. NASDAQ) indicate that equity markets have already recognized these future gains. The recent plans for the establishment of an integrated "European Stock Exchange", initiated by Professor Alexandre Lamfalussy, point to the same direction.

The success of the single currency region in the EU provides a good analogy for the enormous long-term benefits that better integrated capital markets can bring. The European Monetary System (EMS) and the Euro-zone well demonstrate the great information values created by unified price-formation and by standardized clearing protocols of equity markets. More than thirty years ago, Cana- 
dian Professor Robert A. Mundell, an economics Nobel Prize winner in 1999, developed the theoretical foundations of these benefits - as the theory of optimal currency areas (Mundell, 1968).

From an information-theoretical aspect, price-formation in a currency union can also be considered as a significantly more efficient way of coding price signals. In the development of our main argument, the information content of price-formation will be of primary concern.

In the current literature of global finance when discussing the cost of international equity financing, one approach to determining the return on equity is based on modern capital market theory (Shapiro, 1999). The importance of the CAPM for the international firm cannot be denied, however, when compared to purely domestic transactions, all of a sudden numerous complicating factors emerge. The main underlying assumption of the CAPM though, namely that "intelligent risk-averse shareholders will seek to diversify their risks", and as a consequence the only risk that will be rewarded with a risk premium will be "systematic risk", appears to be relevant internationally, too. The risk premium associated with a particular foreign asset is assumed to equal $\beta_{\mathrm{i}}\left(\mathrm{r}_{\mathrm{m}}-\mathrm{r}_{\mathrm{f}}\right)$ where $\beta_{\mathrm{i}}$ is the systematic or non-diversifiable risk of the asset. $\beta$ measures the correlation on a particular asset and the return on the relevant "market portfolio", and $\mathrm{r}_{\mathrm{m}}-\mathrm{r}_{\mathrm{f}}$ is the market risk premium. Shapiro (1999) argues that the relevant or appropriate market portfolio to use in measuring the cost of capital for a foreign subsidiary's beta for instance, depends on one's view of world capital markets. More precisely, it depends on whether or not capital markets are globally integrated. If they are, then the "world portfolio" is the correct choice, if they are not, the correct choice is the domestic portfolio. The test of capital market integration depends on whether these assets are priced in a common context, that is capital markets are integrated to the extent that security prices offer all investors worldwide the same trade-off between systematic risk and real expected return.

In this paper we shall argue that, at present, truth probably lies somewhere in between. Capital markets are now integrated largely, and they can be expected to become even more so with time. However, because of various government regulations and other market imperfections across domestic markets, integration is by far not complete. Unfortunately, it is not currently within our power, if indeed it ever will be, to empirically determine the relevant market portfolio and, hence, the correct beta to use in international equity investments or project evaluation. (It should be added for this matter that the problem of determining the appropriate market portfolio to use in estimating beta arises domestically as well as internationally.)

In the international economics literature, empirical evidence on the applicability of the CAPM to world market is strong, but not overwhelming by any means. 
Strength of models has always been a matter of special assumptions: Solnik (1977), Stulz (1981), Wheatly (1988), Cho et al. (1986), Harvey (1991). Our model in this regard is no exception to this tradition.

Despite the apparent benefits of corporate international diversification for shareholders, the research by Bertrand Jacquillat and Bruno Solnik concluded first in the literature that although multinational firms do provide some diversification for investors, they are poor substitutes for direct international portfolio diversification (Jacquillat and Solnik, 1978). Their results indicate that an internationally diversified portfolio leads to a much greater reduction in variance than does one comprising firms with internationally diversified activities. Thus, the advantages of international portfolio diversification remain.

Based on the concept of global markets, notwithstanding its limitations and the special assumptions attached to the CAPM, for modeling purposes it is reasonable to perceive these markets as an integrated network. The network itself shall be modeled as a communications system. In this communications perspective, the emphasis is on the system's capacity and on performance measured by the amount of information that it can carry. What this particular view of the international equity markets can perhaps offer as a contribution to the existing literature, is the argument that all measures leading to better clearing, smoothing and standardizing information flows will ultimately help the pricing of international risks. With more unified pricing mechanisms, in turn, system performance and capacity utilization can be substantially boosted. A higher-level system capacity utilization will bring lower transaction costs, more liquidity and ultimately more efficient markets, which provide cheaper funds.

The international network of national capital markets will be portrayed as a global communications network, where information flows are in one channel and money in the other. The integration of national capital markets into larger international units, in our view, can improve the system's efficiency. The creation of any larger, yet tightly integrated international system, however, implies the need for some kind of global harmonization and regulation. The identification of this particular need for harmonization and regulation of global equity markets is one of the main arguments carrying practical conclusions of our otherwise theoretical reasoning. The second main argument that may also carry some future policy relevance is related to a desired efficiency improvement of the integrated system itself. In an information-theoretical perspective, an increase in the performance of the distribution system will lead to a massive increase in welfare. Due to internationally standardized ways of measuring and interpreting risk, there can be large distribution improvements expected to lead to more efficiently channeled and - what is more important - cheaper international funds. Efficiency gains realized in information flows can be translated into faster clearing, as well as into lowering 
transaction costs (and ultimately overall prices) of international equity investing. This is the main conclusion that can be drawn from the theoretical reasoning presented next.

In section I, we shall briefly present the logic of a general model of communications network.

In section II, we shall model and interpret international equity markets in a communications system framework. In this particular network perspective, based on the fundamental logic of the measurement of information (Reza, 1992) and on the Capital Asset Pricing Model (CAPM) (Shapiro, 1999), respectively, we shall show that, currently, the loosely-integrated global markets operate at very large losses. Partly because of low efficiency on these markets, pricing risk properly is especially difficult, and consequently the internationally channeled equity funds are relatively expensive.

\section{A GENERAL MODEL OF A COMMUNICATIONS SYSTEM}

Information theory deals with the examination of an information carrier device and with the interpretation and control of the processes within a communications system. The information carrier device or its shape does not necessarily have to be tangible, material-like. Just like the affiliation with another person's thought can be fundamentally looked at as a question of information transfer, and the problem of transferring a visual picture created by art is of the same nature. In each case the "idioms" applied by the language of the transmitter is of a particular kind, one that enables the receiver (decoder) with the capabilities to decipher. Hence, information theory deals with the nature of transfer systems, and not with the specifics of individual messages or their structures; it is the performance of the entire systems that is of interest and not their individual items. As such, information theory is interested in the behavior of the whole system, independently of the variety of the message transmitters or its elements. The general structure figure of a communications system is the following (see Figure 1):



Figure 1. The general structure of a communications system 
The components of the system are original sources, a message-issuer or transmitter; a message receiver, an appliance (receiver of a telephone, TV, computer monitor, etc); and bridging the two is the network providing the transmission.

This description is the simplest of all communications systems. In reality, far more sophisticated systems operate, where large numbers of transmitters and receivers function in a complex system. An example of this system is an electrical network, where distributions systems linked to several power stations are connected to city-sized end-users. A television network is of the same kind, where aerial transmitters, as well as satellite transmitters may be used. In the case of sophisticated large networks, solving the problems of distribution and the efficiency regarding the performance of the system transmitter are obvious. One should aspire to design systems that transmit valuable data, energy or information with sufficient reliability. If the material to be transmitted is material or energy, measurement of efficiency and losses is relatively simple. If it is information, a message of some kind, or intelligence that is to be transmitted, this "simplicity" disappears. How can one measure the quantity of information? On the other hand, being in possession of such a measurement unit, how can the efficiency of a system be improved? In order to see precisely what this is all about; let us use the analogy of examining an electrical energy-supply power system.

If the prime energy source (power station $\mathrm{V}_{\mathrm{s}}$ ) supplies power, the user has to consume a pre-calibrated voltage of $\mathrm{V}_{\mathrm{r}}$. Upon transporting electricity, it is common knowledge that the greatest problem is heat-loss appearing in the cables (the cables are to be considered as parasite consumers). The efficiency of the transmission can be improved by the reduction of heat loss, for example by improving the quality of the cables. Another way is to "transform up" the electricity exiting the power station, later, at terminals located prior to the end users, it is "transformed down", it is made fit for consumption. The question is, whether steps of this kind, or a series of steps similar to this, can be applied in case of information as well. If losses occur in the information transfer channels, is there a way to improve efficiency? It depends on whether any kind of measurement unit for efficiency can be created! For the model-type thinking, the communications system is of statistical nature, therefore it is not deterministic. We should consider the transmitter of the system as a source of various symbols and signals, like the determined characters of an alphabet. The selection of these symbols is the result of a random event, which may correspond to certain statistical rules. The channel transfers the incoming signals to the receiver. The capacity of the channel is also of random nature.

If say character " $A$ " is sent by the transmitter with a probability of $P(A)$, which is transmitted by the channel with the probability of $\mathrm{P}(\mathrm{A} \mid \mathrm{A})$, then the probability of the receiver receiving the sent " $\mathrm{A}$ " clearly, i.e. as an " $\mathrm{A}$ " character, is therefore P (A) P (A $\mid$ A). 
Communication channels generally operate at a loss. Either the transmitted signal does not ever reach the receiving station at all, or it gets there in a distorted form. Spurious signals are always present (i.e. for receiving radio, TV), as say in a one-way street a car coming against the direction of traffic. These spurious, distracting signals are called noise.

One of the main tasks of the designer of communications systems is to minimize the effects of noise or noise sources. In the deterministic system of transmitting electrical energy, we saw that the device meant to improve the efficiency of the system is called the transformer. In information theory, this very same device is called the encoding equipment. Due to its function, the encoded message is less apt to suffer deformation from "noises". The decoder (or the re-transformer) at the receiving station is to reconvert the signals into their original form. For the sake of effective communication, the decoder tries to decipher the transmitted message line with the help of the inverse function of the original input-coding function.

$\begin{array}{llll}\text { Let the coding function be } & F & \mathrm{I} & \mathrm{F}(\mathrm{I}) \text {, } \\ \text { and the decoding function } & \mathrm{F}^{-1} & \mathrm{~F}(\mathrm{I}) & \mathrm{I}\end{array}$

respectively, where $\mathrm{F}+\mathrm{I}$ is the input; $\mathrm{F}(\mathrm{I})$ are the coded or transformed signals or material put into the system; $\mathrm{F}^{-1}$ is the inverse function of $\mathrm{F}$.

This perfect process is hypothetical only, as in practice noise and other spurious factors do not allow perfect communication. It is obvious, that in case of power transmission systems, due to heat loss, $100 \%$ performance is not possible. Consequently, the model in Figure 1 is rather simplified. However, due to its quite general nature, it may be diversely applied. Wiener (1961) had applied this model in a pioneer way, so that it was equipped with statistical (not deterministic) nature. He demonstrated that radio, TV and telegraph stations emit message series of determinable probabilities by a random process out of a well-known transmission dictionary. Therefore, receiving stations in these communications systems can also be determined by statistical methods.

Next, we shall briefly demonstrate with the help of a well-known example, how one can measure information.

Suppose, we have to choose an article from a department store catalogue, that has $n$ number of various models:

$$
\left[\mathrm{x}_{1} ; \mathrm{x}_{2} ; \mathrm{x}_{3} ; \ldots ; \mathrm{x}_{\mathrm{n}}\right]
$$


The information related to the selection of one particular model, $\mathrm{I}\left(\mathrm{x}_{\mathrm{k}}\right)$ is the probability function of selecting the respective $\mathrm{x}_{\mathrm{k}}$ model.

$$
\begin{gathered}
\mathrm{I}\left(\mathrm{x}_{\mathrm{k}}\right)=\mathrm{f}\left(\mathrm{P} \mid\left\{\mathrm{x}_{\mathrm{k}}\right\}\right) \\
\mathrm{I}_{1}\left(\mathrm{x}_{\mathrm{k}}\right)=\mathrm{f}\left(\frac{1}{n}\right)
\end{gathered}
$$

We should furthermore suppose that all models could be ordered in $m$ number of colors. For the sake of simplicity, let us also suppose the selection of each color to be equally probable. Thus the information related to the selection of each color is:

$$
\begin{gathered}
{\left[\mathrm{s}_{1} ; \mathrm{s}_{2} ; \mathrm{s}_{3} ; \ldots ; \mathrm{s}_{\mathrm{m}}\right]} \\
\mathrm{I}_{2}\left(\mathrm{~s}_{\mathrm{j}}\right)=\mathrm{f}\left(\mathrm{P} \mid\left\{\mathrm{s}_{\mathrm{j}}\right\}\right)=\mathrm{f}\left(\frac{1}{m}\right)
\end{gathered}
$$

Where function $f(x)$ is the same unknown function as in $\left[\mathrm{s}_{1} ; \mathrm{s}_{2} ; \mathrm{s}_{3} ; \ldots ; \mathrm{s}_{\mathrm{m}}\right]$.

Next, suppose that the selection can take two different ways.

We first select the model from the catalogue, and later its color, so that the two selections are independent from each other.

We select the desired model with its respective color simultaneously from the $m \cdot n$ choices, where the occurrence of the variants is equiprobable.

At the cognition of the $f(x)$ function's attributes we are supported by an intuitive selection, according to which the contents of the two methods of selecting information are equal, when

$\mathrm{x}_{\mathrm{k}}$ in $\mathrm{s}_{\mathrm{j}}$ color is selected, see [2c] [2d], then

$$
\begin{gathered}
\mathrm{I}\left(\mathrm{x}_{\mathrm{k}} ; \mathrm{s}_{\mathrm{j}}\right)=\mathrm{I}_{1}\left(\mathrm{x}_{\mathrm{k}}\right)+\mathrm{I}_{2}\left(\mathrm{~s}_{\mathrm{j}}\right)=\mathrm{f}\left(\frac{1}{n}\right)+\mathrm{f}\left(\frac{1}{m}\right) \\
\mathrm{I}\left(\mathrm{x}_{\mathrm{k}} ; \mathrm{s}_{\mathrm{j}}\right)=\mathrm{f}\left(\frac{1}{m \cdot n}\right)
\end{gathered}
$$

And therefore

$$
\mathrm{f}\left(\frac{1}{n}\right)+\mathrm{f}\left(\frac{1}{m}\right)=\mathrm{f}\left(\frac{1}{m \cdot n}\right)
$$

This is the functional equation with several solutions, out of which the most important for us is

$$
f(x)=-\lg x
$$


Therefore, when a statistical experiment may have $n$ number of equi-probable solutions, then the quantity of information associated with an event is $\operatorname{lgn}$. The information measured in this way has the favorable property of being also additive in cases of independent events. This special property will be of further, primary relevance and capitalized on when used in the communications model of capital markets.

\section{INTERNATIONAL DISTRIBUTION OF EQUITY FUNDS AND MARKET EFFICIENCY}

Following the introduction of the general model of communications systems, now let us imagine the international equity markets as a system of communications between seekers (transmitters of price signals) and providers of funds (receivers of signals). We assume that this system is an intermediary network of information messages and of money, respectively. The schematic diagram of the system is portrayed in Figure 2.

Let us further suppose that in this network a special double channel (tunnel) transmits money in one direction and information in the other. Earlier, we distinguished two types of selections, $\mathrm{x}_{\mathrm{k}}$ - and $\mathrm{s}_{\mathrm{j}}$, respectively. We now keep this double-track selection.

For our capital market model, we maintain the distinction of two selections, though with different meanings: the selection called " $\mathrm{x}_{\mathrm{k}}$ " type - which earlier meant the choice of products from " $n$ " pieces of catalogue products - from now on will mean the choice of a security (an equity) from a catalogue of international stock listings, and will be denoted by $\mathrm{r}_{\mathrm{k}}$ t the selection called "s, type, (meaning earlier the color,) from now on is considered to be the assumed risk related to the chosen security. The precise meaning of $r_{k}$ is the offered (promised) but not guaranteed future yield at the time of sale of an internationally traded security. The offered return is the calculated internal rate of return within a given period. The $\sigma_{\mathrm{j}}$ is the risk factor that can be related to the particular $\mathrm{r}_{\mathrm{k}}$, the offered (expected) return of security k.

Suppose the equity offer coming from country $A$, promising a future yield of $\mathrm{r}_{\mathrm{k}}{ }^{\mathrm{A}}$, with a $\sigma_{\mathrm{j}}$ risk, respectively, and received as such by country $B$. Then, the message has been "well received", and the sale offer had been found acceptable, thus, the flow of funds has been triggered from country $B$ to $A$, and the international equity investment has been made.

Following the logic of the earlier model, let us again consider a communications system emitting a finite number of discreet investment signals with their related probabilities, 


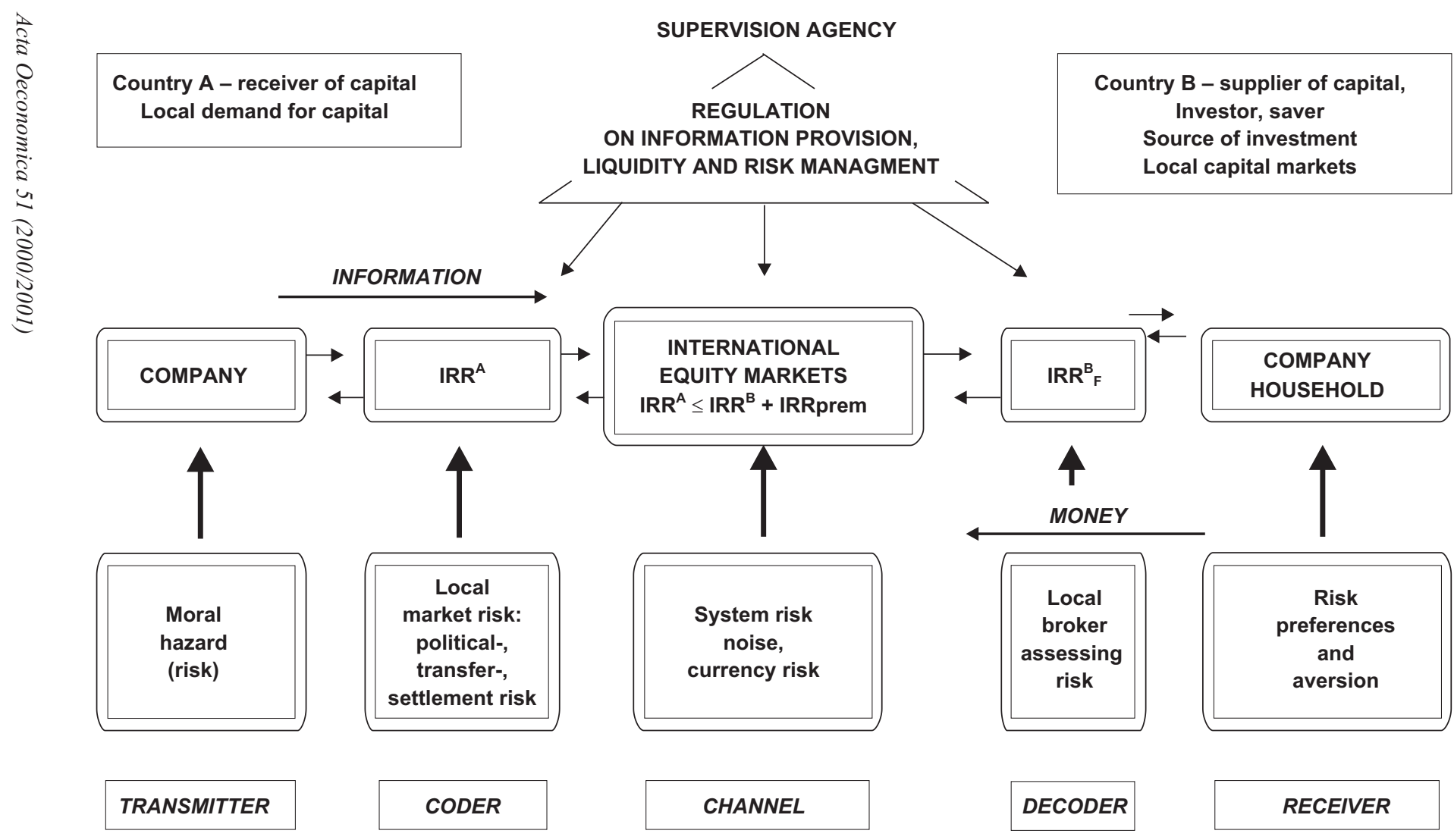

Figure 2. The communications model of international equity markets 


$$
\begin{gathered}
{\left[\mathrm{x}_{1} ; \mathrm{x}_{2} ; \mathrm{x}_{3} ; . . ; \mathrm{x}_{\mathrm{n}}\right]} \\
{\left[\mathrm{P}\left(\mathrm{x}_{1}\right) ; \mathrm{P}\left(\mathrm{x}_{2}\right) ; \mathrm{P}\left(\mathrm{x}_{3}\right) ; \ldots ; \mathrm{P}\left(\mathrm{x}_{\mathrm{n}}\right)\right]}
\end{gathered}
$$

so that the system is selecting at random, and that the selections following each other are independent of each other, with the probability of selecting $\mathrm{x}_{\mathrm{k}}$, being $\mathrm{P}\left(\mathrm{x}_{\mathrm{k}}\right)$. Then, the amount of information related to $\mathrm{x}_{\mathrm{k}}$ as an "investment message", can be defined as follows: ${ }^{2}$

$$
\mathrm{I}_{\mathrm{k}}=-\lg \mathrm{P}\left(\mathrm{x}_{\mathrm{k}}\right)
$$

$\mathrm{I}_{\mathrm{k}}$ is called in professional jargon the self-content of information of the message (self-information).

Investment messages on future yields coming from communications sources have an average information content of:

$$
\mathrm{I}=\mathrm{I}_{\mathrm{k}} \text { statistical mean }=-\sum_{k=1}^{n} \mathrm{P}\left(\mathrm{x}_{\mathrm{k}}\right) \times \lg \mathrm{P}\left(\mathrm{x}_{\mathrm{x}}\right)
$$

I, the general information content of the message, is often also named as the communication entropy of the message source, and is denoted by $H$.

The entropy of the abovementioned communications source is hence:

$$
\mathrm{H}\left(\mathrm{p}_{1} ; \mathrm{p}_{2} ; \mathrm{p}_{3} ; \ldots ; \mathrm{p}_{\mathrm{n}}\right)=-\left(\mathrm{p}_{1} \lg \mathrm{p}_{1}+\mathrm{p}_{2} \lg \mathrm{p}_{2}+\mathrm{p}_{3} \lg \mathrm{p}_{3}+\ldots+\mathrm{p}_{\mathrm{n}} \lg \mathrm{p}_{\mathrm{n}}\right),
$$

where

$$
\mathrm{p}_{1 ;} \mathrm{p}_{2} ; \mathrm{p}_{3} ; \ldots ; \mathrm{p}_{\mathrm{n}}
$$

is a discreet probability distribution.

Let us further consider a similar communications source, signaling $m$ number of symbols, and let $\mathrm{H}(\mathrm{n})$ and $\mathrm{H}(\mathrm{m})$ represent the information content emitted by the two sources. If the two sources emit their respective signals independently of each other, then the joint emission represents " $\mathrm{m} \times \mathrm{n}$ " symbol pairs. The general mean content of information represented by the "signal pairs" emitted by two independent communications sources can be described as:

2 Random selection is a permitted simplification from the point of view of the model, although it is a rare method in the construction of a real-life portfolio. It is in line, however, with the empirically undeniable "random walk", i.e. its coincidental nature of stock prices. Random behavior is especially relevant if one adds the experience of unexpected wild currency fluctuations present on international equity markets but not stipulated in the CAPM model. 


$$
H(m \times n)=H(m)+H(n)
$$

Based upon the previous descriptions, let the signals of the funds-seeking country $A \mathrm{r}_{\mathrm{k}}{ }^{\mathrm{A}}$, be the presumed future yield of the equity; and let $\sigma_{j}^{k}$ be the risk factor (the variance of the yield of this security), defined by an independent security analyst. This implies that on the demand side, the general mean measure of this combined information sent by the fund-seeking country $A$, and by the specialist international broker market, respectively is:

$$
I=H=-\sum_{k=1}^{n} p\left(r_{k}\right) \cdot \lg p\left(r_{k}\right)-\sum_{k=1}^{m} p\left(\delta_{j}^{k}\right) \cdot \lg p\left(\delta_{j}^{k}\right) .
$$

[7] reaches its maximum if $\mathrm{p}\left(\mathrm{r}_{\mathrm{k}}\right)$ and $\mathrm{p}\left(\delta_{j}^{k}\right)$ are normally distributed.

This property of the information-value function [7], capturing a combined measure of expected return and risk would bear special relevance later in discussing the efficiency of the communications system.

In order for this amount of information I to reach the buyer, i.e. the funds-supplier, it would also be necessary for the purchaser of the security to be precisely aware of the discreet probability distributions $\mathrm{p}\left(\mathrm{r}_{\mathrm{k}}\right)$, as well as that of $\mathrm{p}\left(\delta_{j}^{k}\right)$. This assumption on global markets, however, is far too much an illusory expectation.

Why? Simply because there is no perfect decoding, one without "loss" (misinterpretations). Even with quite simple signals, languages and messages perfection is hardly possible. No wonder that perfect reception is especially illusive for sources which emit a host of unknown and "exotic" signals with a large amount of noise. International equity markets are especially good examples for sources generating a lot of noise and signals, which are very difficult to decode. Let us see why.

It has been known for a long time from Black-Jensen-Scholes (1972) that even with the generally accepted assumptions of the CAPM model there are serious concerns on domestic markets whether they can stand all tests searching for empirical evidence. For the CAPM to hold we have to consider now these assumptions:

Assumption I - Investors can choose between portfolios solely on the basis of expected return and variance.

This implies that portfolio returns are normally distributed. Although, this assumption is not unreasonable in some cases, it can become clearly bothering in others (e.g. if there is no bound on highest possible returns; Haugen, 1990). On international markets a series of special concerns arise, Száz (1991), Shapiro (1999), Magas (2000). 
Assumption II - All investors are in agreement regarding the planning horizon and the distributions of security returns.

This implies that investors plan their investments over a single period of time. They also agree on the numbers to be input into their portfolios. Furthermore, they agree on the expected return on each equity. This second assumption seems to be consistent with the next main underlying condition of the CAPM, namely that information about securities flows freely throughout the capital market.

\section{Assumption III - There are no frictions on the capital market.}

This condition means that there are no impediments to the free flow of capital and information. Implicit is in this assumption that there are no transaction costs associated with buying and selling. In addition, it is assumed that there are no taxes imposed.

In general, these assumptions are made so that one can obtain a definitive picture of the relationship between risk and expected return in the market.

In theory, the more homogeneous, developed, and largely capitalized an equity market is, the more one can expect that this market becomes efficient from the information point of view. As a result, it is likely to be true that those sitting at both ends of the market's communication channel understand the sent and received signals as the same. Given this particular efficiency assumption on mature domestic markets, the following questions are now warranted:

At this moment of global financing, does such a fine, say, efficient CAPMtype coding exist on international capital markets? Can, even in theory, any particular scheme of coding investment signals (i.e. pricing) be identified as one that may be uniformly applied, one, which is reliable? In other words, is there any pricing/coding scheme, which may, in good faith, be recommended for today's international equity investors? The answer is clearly negative, no such uniformly applicable, let alone "fool-proof" scheme of pricing, can be identified. Nevertheless, this statement needs further elaboration.

As we saw earlier, assuming an ideal general communications network would mean that: If on the funds-seeking side the coding were<smiles>FP</smiles>

then at the funds-supply side the decoding will be applied
$\mathrm{F}^{-1}$
$\mathrm{F}(\mathrm{I})$
I. 
It appears - although it is by far not explicit - that in an information-theoretical perspective, global market networks distributing international funds raise even more problems than the relatively mature, domestic capital markets themselves do. On the latter, participants know each other better and de facto speak the same "language", and information problems do not tend to overwhelm. That being the case, is it reasonable to argue that due to intensifying global networking efforts, eventually, in the international trade of securities - an efficient market mechanism, one very similar to the CAPM - will necessarily develop? Probably yes, but we cannot tell it for sure.

The currently still widely recognized as theoretically valid - yet empirically non-testable - CAPM states that in the long run, modern, integrated capital markets, in the absence of frictions to the flows of information, are efficient. This means that in the end no sustained yield above the average market yield can be realized. ${ }^{3}$ This particular conclusion of the CAPM model, yet long since known, is simple, although still somewhat surprising. The risk premium of an investment is equal to the average risk premium represented by the market, multiplied by the factor of correlation between the given share and the mean changes of the whole market.

In standard financial language the CAPM relationship can be written as:

$$
\mathrm{r}_{\text {premium }}=\mathrm{r}-\mathrm{r}_{\mathrm{f}}=\beta \times\left(\mathrm{r}_{\mathrm{m}}-\mathrm{r}_{\mathrm{f}}\right)
$$

where $r$ is the yield of the particular security, $r_{f}$ is a risk free yield, e.g. government bond yield, $r_{m}$ is the average yield of the market, $\beta$ is the correlation coefficient between the equity in question and the market (an average of it). ${ }^{4}$

3 The CAPM argument in plain English is the following: there are literally thousands of well-informed intelligent professional investors actively searching for mis-priced securities. Since, upon finding them, these professionals trade and thereby affect prices; it is likely that security prices, at any given time, reflect the collective wisdom of those who invest in them. If information rapidly and efficiently becomes impounded into the prices of securities, then it becomes impossible to beat the market through any form of security analysis. This controversial issue became known as the efficient market controversy, and it still remains to be settled to this day.

4 To be precise, one has to make a more exact statement: the CAPM is valid, and is only valid if the market portfolio is efficient. In an efficient portfolio, a linear relationship exists between the expected yield of the shares and their contribution to the risk of the portfolio. In addition, it needs to be noted that the CAPM is related to the yields expected and not to the yields realized. With respect to reality, it is also a significant simplification that an effective market portfolio contains shares only. Real estate, goods, bonds are excluded, although these are always realistic investment alternatives as well. 
It should not be overlooked that in the case of international equity transactions, quite specific additional complications arise, which significantly differ from the ones present on the "efficient" domestic markets. ${ }^{5}$ On global markets, special complications emerge during both the coding and the decoding of the price signals emitted by the fund-seeking source wishing to sell equity. To bridge somehow the frequently created communication gaps, both international buyers and sellers of equity, and especially those who trade on "exotic markets", develop their own intuitive "language" of pricing. This, of course, itself can create a lot of noise and misunderstanding in international transactions, which can be accepted only if the risk premium may substantially be lifted. Based on the large communication gaps in general, and on the pricing difficulties in particular, it is argued that the general underlying conditions (namely assumptions I, II, and III) that would warrant the application of the CAPM in their pure form, are not present on the international markets.

But even if we accepted, just for the sake of formal logic, the CAPM-model to hold on the international markets, then the following scheme could be considered as a logical "construction" pattern for the "coding" (pricing) of a typical international ("exotic") risk premium.

If $\mathrm{r}^{\mathrm{A}}$, the promised yield offered by the fund seeking country $A$ is accepted, (i.e. financed by country $B$ ), then it can be decomposed as:

$$
\mathrm{r}_{\mathrm{k}}^{\mathrm{A}}=\mathrm{r}^{\mathrm{B}}+\mathrm{r}_{\mathrm{p}}
$$

where

$\mathrm{r}^{\mathrm{B}} \quad$ is the risk free yield in country $B$,

$r_{p}$ is the risk premium required for an international investment,

Assuming the CAPM to apply, this latter term, $\mathrm{r}_{\mathrm{p}}$ can be written as:

$$
\mathrm{r}_{\mathrm{p}}=\beta\left(\mathrm{r}_{\mathrm{m}}-\mathrm{r}_{\mathrm{f}}^{\mathrm{B}}\right)
$$

True, the formula [8a] for the promised (implicit) yield, $\mathrm{r}_{R}{ }^{A}$ may have a sound meaning of future earnings potential, and as such, it may constitute a somehow

5 The need to somehow settle the efficiency debate with testing the efficiency hypothesis has spawned an extremely large number of empirical studies directed at determining the quantity and quality of information reflected in security prices. Initially the weight of the evidence clearly favored the view that the market was highly efficient. At this point, the prevailing view is that the market appears to be clearly more efficient than was prior to the publication of Fama (1965). Security prices reflect less than the complete set of information available to the diligent investor. For more on these empirical results see Black-Jensen-Scholes (1972), Shanken (1987), Tiemann (1988), Chan et al. (1992), Harvey (1991). 
"decodable" signal arriving from country $A$. Nonetheless, it cannot be automatically applied to international transactions, principally for two reasons.

First, the average market rate of return whereby $r_{m}$, which in theory is the return of the efficient market portfolio related to an efficient "benchmark" international market, as of yet, is more fiction than reality. Simply because the CAPM efficiency on international markets - in the strict sense, that is, all the underlying assumptions are being met - is just not delivered. Although the CAPM average and the CAPM formula of pricing ("coding") market risk on developed domestic capital markets, (such as for instance the American, the Japanese or the German) can be of substantial practical use, it is by no means for routine application on international markets. ${ }^{6}$

Second, regardless the legitimacy of an "international" CAPM, there are always some international risks of special kind that are almost always imperfectly captured by what is known as the local "currency risk" (e.g. local market risk, and company-related, local moral hazards, and politics-related country risks, in addition to settlement- and transfer-related risks). Consequently, these special risks cannot be easily diversified away. (On how they feed into the information flows see Figure 2.) Thus, from the pure information-theoretical point of view, all international risks cannot even be adequately accounted for. Practically, it means that they cannot be coded/priced in a standard way. From the average investor's point of view the fact that international equity markets are becoming increasingly global, does not mean that they become globally efficient at the same time. Unlike under the CAPM, global investors may have different views concerning both risk and return. Hence, at present, global market networks cannot be regarded by any measure as efficient and "uniformly coded" communications systems. This means that participants of these markets are unable to safeguard - by any proven coding algorithm - against specific system risks arising in local markets or against noises generated within the network. Therefore, what remains is a traditional or intuitive approach to capturing acceptable risks related to the international exchange of funds. For practical purposes this leads us to believe that, at the moment, there is no efficient market mechanism with a proven track record, which could forecast globally achievable opportunities of significant gains, or could safely moderate (diversify away) large losses. Although the CAPM is a widely recognized theoretical model of rational choice on the developed domestic equity markets, it cannot be blindly or automatically relied on by international investors. To conclude, from a pure information-theoretical point of view it can be argued that the existing distribution mechanisms of international equity markets are necessarily operating at

6 For the back-up of this point and the empirical observations in details, see: Haugen (1990), Brealy and Myers (1992), Shapiro (1999). 
very large losses. In other words, the capacity utilization of this imperfect international market system is very poor. For the full comprehension of this statement, let us refer to two efficiency concepts, namely to those of the absolute and the relative redundancy, respectively. With the help of these notions, the efficiency of a communications system can be well measured.

Following standard definitions of a communications system's efficiency (Reza, 1992), a system is meant to be the more efficient, the less absolute redundancy it contains. Denoting the maximum capacity of information transfer of a system $C_{\max }=I_{m}$, and its virtually used capacity $I_{v}$, (their amounts of information, respectively), one can define absolute redundancy.

Let $\mathrm{R}^{\mathrm{A}}$ be the absolute redundancy of a communications system, that is the difference between its maximum and virtually used capacity,

$$
\mathrm{R}^{\mathrm{A}}=\mathrm{I}_{\mathrm{m}}-\mathrm{I}_{\mathrm{v}}
$$

In the case of international equity markets, based on the meaning of equations [7], [8a] and [8b] in particular, the absolute redundancy of the system, that is the difference between maximum and actual capacity, is very large. Primarily because normal distribution for portfolio returns across national markets cannot be expected. This international market system - due to excessive losses and noise operates very inefficiently.

Using another measure related to the efficiency of the system, relative redundancy, that is the ratio of absolute redundancy to capacity, we arrive at the same conclusion. Based on the ratio of the difference between the potential and actual capacities to maximum capacity, one can state that if $I_{m}-I_{v}$ is large and increasing - due to excessive losses - the performance of the system is weak.

$$
\frac{I_{m}-I_{v}}{I_{m}}=1-\frac{I_{v}}{I_{m}}
$$

As it is expressed in equation [10], the relative redundancy will decrease if the system operates more economically. If the value of the expression in [10], the level of relative redundancy stays close to unit, then information losses are still high. This implies that coding (pricing) is imperfect. The more ambiguity the system carries, the less error-free the flow of information related to capital flow happens to be. In short, as long as the difference of $I_{m}-I_{v}$ does not decrease, the communications system functions ineffectively with a high level of absolute redundancy. The practical meaning of this is that, at present, the international network of trading equities, as a communications system operates with a lot of loss (non-specifiable risks). Information about securities does not flow freely and the use of the system is relatively expensive. The generation and translation of 
information related to risk and return is not confined to standard practices and rules.

A harmonization of rules managing risk as well as the protocols of trading equities internationally would enhance the specification and the pricing of risk.

In this regard, one should think of regulatory measures that they tighten transparency standards in particular for brokerage firms and banks. These safety measures will all contribute to helping the information flows related to the assessment and to the pricing of risks. In addition, bigger international markets with a more homogeneous set of rules will generate economies of scale in both buying and selling as well as in transmitting information. For this reason, changes that from an information-handling point of view will lead to a more homogeneous world equity market should be encouraged. These changes will enable the system to carry lower transmission (transaction) costs and cheaper funds allowing a more reliable, i.e. uninterrupted flow of both money and information.

\section{SUMMARY AND FINAL CONCLUSION}

For the applicability of the CAPM to world markets, we have modeled international equity markets as an integrated network. To justify its standard assumptions (namely, a/ that inventors choose between portfolios solely on the basis of expected return and variance; $\mathrm{b} /$ that they are in an agreement regarding the planing horizons and the distribution of security returns; $c$ / that there are no frictions on the capital market) is not without serious limitations. For modeling purposes, however, the allowances made with the assumptions have been of some use. The CAPM-based communication model has yielded some useful insights into the efficiency problems that international markets carry.

The communicational efficiency and operation of an international market system, from the point of view of information flows, is the better the less absolute redundancy it contains. In the case of international equity markets, based on the meaning of equations [7], [8a] and [8b] in particular, the absolute redundancy of the system, that is the difference between maximum and actual capacity, is very large. This system operates inefficiently due to excessive losses. The integration of national equity markets into larger and more homogenized units could improve the system's performance. The creation of such an integrated international system, however, implies the need for some kind of global harmonization and regulation of equity markets. Global regulation would apparently lead to more effective international price formation, which in turn would improve the flows of information. Standardization of the coding of pricing signals alone will boost the efficiency of the system. The desired efficiency improvement, eventually, will mean 
less risk and cheaper funds. Needless to say, the formation of an entirely standardized and integrated international capital markets network will only be possible in the very distant future. Yet, there are obvious signs that larger units are more efficient: the recent merger initiatives of leading European stock exchanges and the Lámfalussy plan for a "European Stock Exchange" clearly point to this attempt. In global markets today, significant dissimilarities still exist in the national regulations, in the bookkeeping standards and especially in the management of information concerning risk. For this reason, it can be argued that the introduction of truly global and mutually accepted safe trading standards should certainly increase the efficiency of international capital markets. Efficiency improvement will enable international markets to clear faster, as well as to lower transaction costs and, ultimately, to reduce prices of international equity investing. In sum, from the perspective of the information theory, any increase in the performance of international equity markets, which is due to harmonization (standardization) of coding risk will lead to an increase in welfare, because of the faster distribution of cheaper international funds. That is the practical meaning of our information-theoretical reasoning which may carry some relevance to international policymakers.

\section{ACKNOWLEDGEMENTS}

The author would like to thank Professor Tamás Szentes, Mr. Krisztián Csubák and Mr. Péter Bárczy for their comments and criticism to help finalize some debated points of earlier versions of this paper.

In addition, special thanks are due to the unknown referees who with their useful comments and criticism have contributed to a large extent to the refinement of the communications model and to the strengthening of some key points.

\section{REFERENCES}

Ashby, W. R. (1964): Introductory Remarks at Panel Discussion. In: Mesarovic, M. D. (ed.): Views on General System Theory. New York: Wiley.

Black, F., Jensen, M. C. and Scholes, M. (1972): The Capital Asset Pricing Model: Some Empirical Tests. In: Jensen (ed): Studies in Theory of Capital Markets. New York: Praeger.

Black, F. (1974): International Capital Market Equilibrium with Investment Barriers. Journal of Financial Economics, December, 337-352.

Brealey, R. A. and Myers, S. C. (1992): Principles of Corporate Finance. New York: McGraw Hill.

Bródy, A. (1998): Theory Neumann, Leontief. In: Papers presented at the 50th Jubilee Conference of the Budapest University of Economics. Budapest: BKE, Vol. II, 771-788 (in Hungarian).

Chan, K. C. G., Karolyi, A. and Stulz, R. M. (1992): Global Financial Markets and the Risk Premium on U.S. Equity. Journal of Financial Economics, October, 137-167. 
Cho, Ch. D., Cheol, S. Eun and Senbe, L. W. (1986): International Arbitrage Pricing Theory: An Empirical Investigation. Journal of Finance, 41: 313-330.

Eichengreen, B. (1999): Toward a New International Financial Architecture: A Practical Post-Asia Agenda. Washington D.C.: Institute for International Economics.

Fama, E. F. (1965): The Behavior of Stock Prices. Journal of Business, January, 45-60.

Fama, E. F. (1970): Efficient Capital Markets: A Review of Theory and Empirical Work. Journal of Business, May, 225-241.

Friedman, M. (1992): The Quantity Theory of Money. In: Newman, P. et al. (eds): The New Palgrave Dictionary of Money and Finance. London: Macmillan Press Ltd., 247-267.

Gray, H. P. (1999): Global Economic Involvement, a Synthesis of Modern International Economics. Copenhagen: Copenhagen Business School Press.

Harsányi, J. C. (1990): Advances in Understanding Rational Behavior. In: Moser, P. (ed): Rationality in Action. Cambridge, Mass.: Cambridge University Press.

Harvey, C. R. (1991): The World Price of Covariance Risk. Journal of Finance, 46: 111-157.

Haugen, R. A. (1990): Modern Investment Theory. 2nd edition. London: Prentice Hall.

Khoury, S. J. (ed) (1991): Recent Developments in International Banking and Finance, Vol. IV-V. Amsterdam, New York, Toronto: North-Holland.

Jacquillat, B. and Solnik, B. H. (1978): Multinationals are Poor Tools for Diversification. Journal of Portfolio Management, Winter, 8-12.

Lucas, R. E. (1992): Studies in Business Cycle. Cambridge, Mass.: MIT Press.

Lucas, R. E. (1996): Nobel Lecture: Monetary Neutrality. Journal of Political Economy, 104: 661-682.

Magas, I. (2000): The Impact of Capital Flows on Emerging Markets. In: Bara, Z. and Csaba, L. (eds): Small Economies' Adjustment to Global Challenges. Budapest: Aula, 341-356.

Mundell, R. A. (1961): A Theory of Optimum Currency Areas,. American Economic Review, 51: 509-517.

Mundell, R. A. (1968): International Economics. New York: Macmillan.

Reza, F. M. (1992): An Introduction to Information Theory. New York: Dover Publications Inc.

Shanken, J. (1987): Multivariate Proxies and Asset Pricing Relations. Journal of Financial Economics, 18

Shapiro, A. C. (1999): Multinational Financial Management. London: Prentice Hall.

Solnik, B. H. (1977): Testing International Asset Pricing: Some Pessimistic Views. Journal of Finance, May, 503-512.

Stulz, R. M. (1981): A Model of International Asset Pricing. Journal of Financial Economics, December, 383-406.

Száz, J. (1991): Hitel, pénz, tőke (Credit, Money and Capital, The Time Dimension of Money and Loan Capital). 3rd ed. Budapest: Közgazdasági és Jogi Könyvkiadó.

Tiemann, J. (1988): Exact Arbitrage Pricing and the Minimum Frontier. Journal of Finance, June, $22-48$.

Wheatley, S. (1988): Some Tests of International Equity Integration. Journal of Financial Economics, 21: 177-212.

Wiener, J. (1961): Cybernetics or Control and Communication in the Animal and the Machine, 2nd edition. Cambridge, Mass.: The MIT Press. 